\title{
Continuing professional development and challenges facing newly graduated midwives in Papua New Guinea.
}

\author{
Alison MOORES ${ }^{1}$, Paula PUAWE ${ }^{2}$, Nancy BUASI ${ }^{3}$, Florence WEST ${ }^{1}$, Mary K SAMOR ${ }^{4}$, Nina \\ JOSEPH $^{5}$, Michele RUMSEY ${ }^{1}$, Angela DAWSON ${ }^{1}$, Caroline SE HOMER ${ }^{1}$ \\ ${ }^{1}$ WHO Collaborating Centre, University of Technology Sydney, Australia. ${ }^{2}$ University of Goroka, Goroka, Papua New \\ Guinea. ${ }^{3}$ University of Papua New Guinea, Port Moresby, Papua New Guinea. ${ }^{4}$ National Department of Health, Port \\ Moresby, Papua New Guinea. 5Papua New Guinea Nursing Council, Port Moresby, Papua New Guinea.
}

\begin{abstract}
:
Background: The Maternal Mortality Ratio (MMR) in Papua New Guinea (PNG) in 2008 was estimated at more than 700 deaths per 100,000 live births. In recognition of the high MMR, a Ministerial Taskforce was established in 2009 with recommendations to urgently address the workforce capacity in regard to maternal and child health services. In 2010, a new competency-based Bachelor of Midwifery curriculum was introduced into four universities in PNG and an increase in the numbers of midwifery students took place over a four year period.
\end{abstract}

Aim: The aim of this study was to explore the experiences of Papua New Guinean midwifery graduates from the 2012 and 2013 Bachelor of Midwifery cohorts. These graduates were among the first to complete the revised national midwifery curriculum designed to improve the knowledge and skills of a registered midwife graduate.

Methods: A descriptive exploratory study was undertaken to explore the experiences of 174 graduates in the first two years post-graduation. All graduates who were able to be contacted were provided with information about the study, consented and were interviewed either face-to-face or by phone/email. Quantitative data were analysed using simple descriptive statistics in SPSS and qualitative data underwent content analysis and coding by the research team.

Findings: Almost all (90\%) graduates contacted were working as midwives with $39 \%$ working in rural and remote locations across PNG. Midwifery education prepared graduates well for their work as midwives, but many commented that the course needed to be longer to improve feelings of competence. Professional support during their graduate year varied depending on location and motivation of supervisors. Many graduates, particularly those in rural areas, expressed the desire to work under clinical supervision in a hospital setting for a period of 6-12 months at the end of their training to become more skilled and confident prior to seeking employment.

Conclusion: Most midwifery graduates from the new curriculum found employment as midwives. Only a minority of graduates have had opportunities for continued professional development or support from a mentor of senior colleague. Regular, ongoing professional development and supervision needs to be initiated for the provision of skilled and evidence based care. Support and incentives for staff to work in rural and remote areas should be considered.

Key Words: midwifery, midwifery education, education, continuing, new graduate experiences

\section{BACKGROUND}

Papua New Guinea (PNG) lies north of Australia and is the largest of the Pacific nations, with a population of over 7 million people with the majority (more than 80\%) living in rural, remote, mountainous and island communities.
Approximately 250,000 babies are born each year and there is a critical shortage of midwives. In 2009, it was estimated that there were 292 registered midwives in PNG, with $44 \%$ of these due to retire in the following decade. ${ }^{1}$ Of these, only 152 were thought to be practising midwifery. ${ }^{2}$ Registration and regulation processes in PNG have improved considerably in 
the last decade, yet it is still unclear as to how many midwives are practising. ${ }^{3}$ Current estimates put the number of registered midwives at 765 , although they may not all be practising midwifery. ${ }^{3}$ The majority of health workers in rural areas are Community Health Workers (CHW) but some health centres also have registered nurses. Community Health Workers and registered nurses often provide maternity services due to the lack of midwives.

Maternal and newborn health key indicators in PNG deteriorated between 1996 and 2008. In 2008, the Maternal Mortality Ratio (MMR) was estimated to be 773 per 100,000 births, ${ }^{4}$ second only to Afghanistan in the Asia-Pacific region (National Department of Health, 2009). In 2009, a Ministerial Taskforce was established to address the poor state of maternal health. The Taskforce made strong recommendations to address the need to increase capacity in emergency obstetric care and access to family planning services. ${ }^{5}$ The Taskforce realised that services needed to be accessible for women and recommended the strengthening of maternal health services at the district level with a goal of one registered midwife at every health centre by 2020.

Prior to the Taskforce's recognition of the urgent need for increased numbers of midwives, a review of the midwifery education standards and programs in PNG was undertaken. ${ }^{6}$ The review made a number of recommendations to improve midwifery education. These included increasing the length of the pre-registration midwifery programs to 12 months; increasing emergency management content; modernising teaching and learning approaches; aligning programs with the International Confederation of Midwives Education Standards; and, improving regulation and registration processes. ${ }^{6}$ These recommendations informed the development and implementation of a competency-based curriculum framework designed to improve underpinning knowledge and skills of midwives with an ultimate goal of improving maternal and newborn health. Four schools of midwifery commenced the new curriculum in $2010 .{ }^{7}$

Between 2012-2015, 394 midwives were educated under the new curriculum and these now represent $56 \%$ of the estimated current midwifery workforce. ${ }^{7}$ All midwives who successfully completed their education through programs utilising the new curricula were formally registered. ${ }^{8}$ This level of registration is significant as prior to the introduction of the new curriculum many midwifery graduates did not, or were not able to, register with the PNG Nursing Council.

These new midwifery graduates are now practising across the country mostly in midwifery roles. Of the 174 graduates who studied in 2012 and 2013, 72 (41\%) were working in the rural areas. ${ }^{9}$ Previous research has examined this cohort's motivations to study midwifery. It was found that a major motivation was to address the high maternal mortality in their communities by increasing their midwifery skills and knowledge.10 After graduation, this cohort of midwives reported increased skill acquisition and confidence; confidence to be leaders in maternal and newborn care services; and, a commitment to the provision of respectful care to women. ${ }^{9}$ What was not examined in these previous studies was the availability of, and the differing levels of support accessible to the new graduates. Further to this, it was not known what continuing professional development opportunities were provided to graduate midwives, some of whom were practising as the sole maternity practitioner in rural areas. Therefore, the aim of this research was to examine the experiences of new graduate midwives in relation to their professional support available, access to continuing professional development and major challenges in their first two years of midwifery practice.

Corresponding author: Caroline SE Homer,

caroline.homer@uts.edu.au

Received: 19.06.2016; Published: 30.12.16

Citation: Moores A, et al. Continuing professional development and challenges facing newly graduated midwives in Papua New Guinea. Pacific Journal of Reproductive Health 2016; 1(4): DOI: $10.18313 /$ pjrh.2016.913

Copyright: (C) 2016 Moores A, et al. This is an open-access article distributed under the terms of the Creative Commons Attribution License, which permits unrestricted use, distribution, and reproduction in any medium, provided the original author and source are credited. 


\section{METHODS}

\section{Design}

A descriptive exploratory methodology was used. Descriptive exploratory methodology is particularly useful in answering research questions that are concerned with people's response to an event or how they feel about a particular event.11 A questionnaire was used to collect relevant information from the midwives. The questionnaire was either self-administered, or, where it was not possible to meet face-to-face with the midwife, the questionnaire was administered and answers recorded over the phone.

\section{Ethical approval}

Permission to conduct this research was obtained from the PNG Medical Research Advisory Committee and ratified by the university's Human Research Ethics Committee (MRAC No. 11.36 - 2011-2013).

\section{Recruitment process}

A total of 181 midwifery students commenced their training in the four PNG midwifery schools in 2012 and 2013. Of these, 174 graduated (4\% attrition rate) at the end of the 12-month program. Attempts to contact all 174 midwifery graduates were made either by telephone or email, although electronic and telecommunication in PNG can be extremely challenging. The PNG research team travelled to smaller townships and assisted in locating graduates using local knowledge and networks. In total, $98 \%(n=170)$ of graduates' locations were confirmed although not all could be contacted.

Once contacted, participants were provided with information about the research and consent was obtained. An opportunity was provided for questions about the research and the participants were reassured that results would be de-identified and would remain confidential. During the research design process, all necessary forms and questionnaires were developed for use in the PNG context. Members of the research team were PNG nationals and ensured that the participant information sheet, the consent form and the survey questionnaire were developed using culturally appropriate terms and questions thus ensuring a culturally respectful and acceptable approach.

\section{Response rate}

Of the 174 graduates, 138 (79\%) were contacted and all consented to be part of the study. None of the graduates contacted refused to take place. Graduates came from each of the four midwifery training schools and data were collected from November 2014 to April 2015. A sensitive cultural approach was maintained to gain trust of graduates that ensured the graduate felt safe to share all relevant information. The researchers were all familiar with the system of maternity care and midwifery education in PNG and thus were able to demonstrate an understanding of, and respect for, cultural requirements.

\section{Data collection processes}

Two PNG researchers and one international member of the team were able to travel to five provincial towns and cities where clusters of graduates were located. Fifty-five (40\%) written surveys were completed. The remaining 83 $(60 \%)$ surveys were completed by telephone. Members of the research team conducted the telephone interviews and all were briefed in the method and content of the survey to ensure consistency among researchers. The survey questions were read out over the phone by the researcher and responses were recorded verbatim on the survey form.

\section{Data analysis}

All survey responses were initially entered into Excel spread sheets. Quantitative data was uploaded into SPSS and analysed using simple descriptive statistics. Qualitative data underwent content analysis and coding by the research team. Content analysis was repeated by small teams within the research team for cross validation.

\section{FINDINGS}

Almost all respondents (89\%; $n=123$ ) were working as midwives with more than one third $(39 \% ; n=54)$ based in rural areas. Rural graduates generally worked as the only midwife and/or as the officer-in-charge in their facility or the sister-in-charge of the labour ward. New graduates were given significant responsibilities for complex care often with little support available to them. The majority of those working in rural areas spent more than $50 \%$ of their time caring for childbearing women and their 
families. The remainder of their time was spent doing general nursing duties.

A desire to serve the PNG rural majority population was identified by a number of graduates who were working in challenging locations. Many $(47 \% ; n=65)$ respondents expressed an understanding of the dire need of women in all areas to have quality midwifery care. One rural midwife explained:

"These are our people. We need to go and help our own people. A lot of women are dying out here"

Other respondents (33\%; n-45) reported efforts to improve outcomes for childbearing women and their babies, often with minimal resources or support. Figure 1 explains the changes one graduate is making in her remote location.

\section{Professional support}

Graduates were asked about the availability of professional support in their workplace to help them develop their clinical skills. Almost twothirds of graduates $(87,63 \%)$ had someone assisting them develop their skills. This was most often a more experienced midwife (50\%; $\mathrm{n}=69) ;$ a medical doctor $(17 \% ; \mathrm{n}=24)$; and, sometimes both $(22 \% ; n=30)$. Unfortunately, 50 graduates $(37 \%)$ stated that no-one was available to support them and to assist with their ongoing professional development as a midwife.

The ongoing professional support received by the graduates was categorised in order of frequency of comments (Table 1). The majority of responses related to clinical assistance and supervision given in the development of skills, particularly for complicated births.

A number $(12 \% ; n=17)$ commented on the support of a mentor who particularly encouraged them to not only develop their clinical skills but also to use share new skills and knowledge with other health workers.

Graduates commented that being supported to practice to their full scope of practice gave them confidence in their own ability. Others identified that senior clinicians were helpful and supportive and were able to give them advice or answer their questions, either in person or over the phone.
Figure 1: The story of the experiences faced by one new graduate based in a rural area

Rachel* works at a remote Health Sub-Centre and is the only midwife and works with one Community Health Worker (CHW). She volunteered to go to this remote place to help the mothers there who were having to pay a considerable amount to travel to another health centre to give birth. When Rachel arrived in her current location, there were no maternal health services available. She began working with the community to increase awareness about the importance of antenatal care, supervised births and family planning. She teaches local volunteers about safe motherhood. Rachel commenced antenatal clinics and a couple of months later she opened a labour room and began to assist women in labour and at birth.

Since Rachel arrived, she has worked tirelessly with the local women and the community to improve care during pregnancy and birth. She reports more women are coming for antenatal care and most are coming to the health centre to give birth. "Sometimes they deliver at other health centres, but they come to me for antenatal clinic (ANC) because of the care they receive". Women are beginning to see the benefit of family planning and are accessing these services as well. Rachel has been able to initiate improvements despite community and personal difficulties. She reports feeling isolated as a new graduate midwife posted in a remote setting with no supervision or support readily available. Communication was challenging as she did not speak the local language. She also experienced a number of challenges in relation to resources; limited health equipment, a lack of staffing and even water supplies were limited at times. Rachel stated that "for the first few months, I was lost".

Although challenging she feels that facing her hardships have made her stronger as a midwife. "I can do procedures that I had never done. I have confidence to care for women and to call for help/advice when I need it". This is helping her to improve maternal health in her area preventing maternal deaths and saving lives.

* Name changed. Story told with permission 
Table 1: Type of professional support received

\begin{tabular}{|l|c|}
\hline Type of support received & $\begin{array}{c}\text { Number of } \\
\text { responses }\end{array}$ \\
\hline $\begin{array}{l}\text { Clinical assistance, supervision or } \\
\text { advice re complicated births }\end{array}$ & 46 \\
\hline $\begin{array}{l}\text { Mentor / Encourage / Develop } \\
\text { my confidence }\end{array}$ & 17 \\
\hline Answer questions/advise/teach & 12 \\
\hline $\begin{array}{l}\text { I was the only midwife / no one } \\
\text { provided support }\end{array}$ & 11 \\
\hline $\begin{array}{l}\text { Give me a hard time (other } \\
\text { midwives) }\end{array}$ & 2 \\
\hline I teach older midwives & 2 \\
\hline Advice over phone & 1 \\
\hline $\begin{array}{l}\text { Help with preparing lessons } \\
\text { (educator) }\end{array}$ & 1 \\
\hline How to use limited resources & $\mathbf{9 7}$ \\
\hline $\begin{array}{l}\text { Midwives not allowed to do } \\
\text { advanced skills that they were } \\
\text { taught }\end{array}$ & 1 \\
\hline Total responses & \\
\hline
\end{tabular}

Note: Graduates could state more than one form of support was received

Graduates felt that the support they received from senior midwives and doctors was vital in order for them to practice what they had learned. Many graduates found it challenging when they returned after their training to their respective places of employment and were not able to implement the evidence-based practice they had learned. However, $86 \%(n=119)$ of respondents stated that they were able to practice the evidence based skills that they were taught during their midwifery program. Just over $20 \%(n=30)$ of respondents felt that it was their responsibility to teach others. Graduates reported that once they had role modelled the new skills and evidence-based practice they had learned, most staff were supportive of changes to practice. Conversely, fewer graduates (18\%; $\mathrm{n}=25$ ) experienced opposition from other colleagues when introducing evidence-based practice. Respondents commented that other staff, particularly midwives were not happy to change and a lack of support made this more difficult. Graduates stated that:

"We do it (evidence-based practice) only when we are not busy. We introduce women to the environment and greet them. We use the lithotomy position, not other positions - I was told by the supervisor and the Community Health Worker to do this. Maybe because we are not considering the woman. I do not feel good about it."

"Our senior midwives are set on doing things the old way and when we want to change their mindset, it's hard"

\section{A desire to work to the full scope of practice as a midwife}

While those in rural areas often worked alone and used their newly developed midwifery skills, others in provincial urban hospitals reported that they could not practice skills they were taught such as manual removal of the placenta or vacuum assisted birth as the obstetricians performed those skills.

Some graduates $(n=28,20 \%)$ felt that they would have benefitted from further clinical practice in urban hospitals before returning to the rural areas to so as to become more confident with advanced clinical skills. In response to how well graduates felt prepared to work in rural/remote areas on graduation, they stated:

"I feel that I need to work close to doctors/consultants and gain more experience before I go out to the very remote areas to help the mothers and babies out there"

"Spend longer at a hospital setting 6-12 months before going back to a rural area"

"If I gain more practice and become confident then I thought of going out to the rural facilities and work"

There was a need for clarity and consensus concerning the role of a midwife. A written scope of practice was seen as necessary guide for both the education a midwife receives and midwifery practice after graduation.

\section{Experiences with having designated positions for midwives}

Registered midwives are classified as a 'specialist nurse' in PNG and all graduates are registered nurses before undertaking their midwifery training. The Ministry of Health determines how many midwifery positions can be filled at each health facility. Some $(7 \% ; n=10)$ graduates were unable to secure a midwifery 
position and were employed in a registered nurse position. This meant that they were not classified as a midwife and were not paid at the higher rate for their post graduate qualifications. Despite not being recognised and remunerated for the appropriate award classification, these graduates were performing the role of a midwife. Graduates were disheartened that they were not being rewarded with the title of midwife and paid the wage they deserved.

There was consensus among the graduates that incentives were needed to attract midwives to rural and remote areas. They felt that essential midwifery equipment should be available to enable them to provide quality midwifery care. Graduates expressed the need for "midwife only" designated positions in rural areas and also expressed the need for incentives to encourage midwives to go to areas of need:

"Provide transport, housing and incentives for midwives so that they could go out to rural areas"

"After graduation, all students need to go to a rural area, with the equipment needed for a midwife e.g. vacuum kit. All health centres must have a midwife if you are going to help women stop dying"

"Students should sign an agreement that they will go to the rural areas"

\section{A need for practical resources}

A lack of resources and equipment meant that graduates were not able to apply the knowledge they had gained in their training. For example, one graduate reported that her health centre did not have supplies of oxytocin for up to three months, and although she had learned how to manage third stage physiologically, without oxytocin, she felt that in the event of a postpartum haemorrhage, appropriate first-line emergency management would be compromised. Others found it difficult to maintain cleanliness and appropriate levels of hygiene when there was inadequate water supply in the labour ward. Without the necessary equipment and resources, the graduates could not apply the evidencebased practices they had learned in their training. One graduate explained:

"We are mentally prepared to work with whatever resources available, but sometimes my care can be hindered by the health care system of the country".

Another limited resource was staff housing, particularly in locations which were in desperate need of midwives. Some of the graduates were not able to return to their original place of employment, or continue in a rural area because of a lack of staff housing. One midwife was volunteering at an aid post close to her home because there was no staff housing at the health centre where she hoped to be employed.

\section{Continuing Professional Development}

Graduates were asked if they had undertaken any continuing professional development since graduation. This included either attending courses or receiving in-service training. The midwives were also asked to indicate the topic of professional development activity they attended (Table 2). More than half (58\%; $n=80)$ had received no further professional development or education since graduating. One graduate commented that her supervisor told her she did not need any further training as she had just graduated. Only 48 (35\%) stated that they had updates relevant to midwifery practice. The remainder of graduates had received updates in general nursing, management or preceptorship.

The limited continuing professional development opportunities were particularly evident in rural areas. Graduates in urban provincial hospitals reported that there were inservice sessions and case discussions available.

Table 1: Training activities since graduation

\begin{tabular}{|l|l|}
\hline $\begin{array}{l}\text { What training activities have } \\
\text { you been involved in? }\end{array}$ & $\begin{array}{l}\text { Number (\%) } \\
\text { of responses }\end{array}$ \\
\hline None & $\begin{array}{l}80 \text { (58) of all } \\
\text { surveyed }\end{array}$ \\
\hline $\begin{array}{l}\text { Midwifery related - includes EOC*, } \\
\text { EmONC**, neonatal, family } \\
\text { planning/sexual health }\end{array}$ & $\begin{array}{l}37(48) \text { of all } \\
\text { positive } \\
\text { responses }\end{array}$ \\
\hline $\begin{array}{l}\text { General topics - includes T.B., } \\
\text { Cancer, General Nursing }\end{array}$ & $14(18)$ \\
\hline $\begin{array}{l}\text { Prevention of Parent to Child } \\
\text { Transmission of HIV/AIDS and HIV } \\
\text { training }\end{array}$ & $11(14)$ \\
\hline Preceptor / Education skills & $10(13)$ \\
\hline Management skills & $3(4)$ \\
\hline Paediatric & $1(1)$ \\
\hline Self-improvement/ reading & $1(1)$ \\
\hline
\end{tabular}

*EOC - Essential Obstetric Care

**EmONC - Emergency Obstetric and Newborn Care 
However, there were few or no opportunities for short courses or more formal learning. The ability to access and attend formal learning opportunities was often restricted by funding and transport issues. Many graduates expressed the desire to study midwifery at a master's level but this program is not available in PNG.

There were 32 comments concerning the need for continuing professional development and support for both graduates and experienced staff. These responses identified the need for career pathways for midwifery graduates. Many expressed the need for a formal graduate support program.

This included suggestions such as the provision of an initial 6-12 month internship at a larger hospital prior to employment in a rural or remote health service; supportive supervisory visits to new graduates working in rural services; annual Emergency Obstetric and Neonatal Course (EmONC) training; and, further formal education opportunities.

\section{DISCUSSION}

This research highlights the challenges facing newly graduated midwives in a low income setting such as Papua New Guinea. In their initial years of practice, graduates were confronted with a lack of professional support; difficulties implementing the evidence-based practice they had learned; challenges working to their full scope of practice; and, problems with a lack of resources such as equipment, medications, running water and housing availability. In addition, limited opportunities for continuing professional development, both formal and informal, meant that the skills and knowledge learned in their midwifery education could not be applied and developed. In particular, more than half $(58 \% ; n=80)$ of graduates reported having no professional development activities since completion of their studies.

A review of barriers to the provision of quality midwifery care in low and middle income countries identified the lack of access to continuing professional development as a barrier to quality care. ${ }^{12}$ Continuing professional development is recognised as an essential component of being a health professional and is a mandated requirement in many regulated professions such as midwifery, nursing, medicine and allied health in countries including Australia. ${ }^{13}$ The International Confederation of
Midwives identify continuing education/professional development as an important component of the Global Standards for Midwifery Regulation and support the inclusion of continuing professional development in midwifery regulation practices. ${ }^{14,15}$ Continuing professional development contributes to maintaining and increasing competence in practice professions and as such is regulated in many countries. ${ }^{16}$

In addition to international recommendations for continuing professional development, many countries also provide a supported new graduate program for health graduates. Graduate support programs are common in high income countries and the evaluation of such programs indicates that the support has resulted in more confident and competent midwives. ${ }^{17-20}$ These programs often involve rotations to various areas of a maternity unit, supported study days, mentorship and an opportunity for graduates to practise and consolidate their skills in a supported environment.21 However, such programs are uncommon in literature from Low and Middle Income Countries (LMIC). Research in Sierra Leone demonstrated that informal support for midwifery staff encouraged mentoring and professional development.22 No studies could be found that particularly supported new midwifery graduates in LMIC.

Given the advanced skills and responsibilities required of midwives in most LMIC it would seem crucial that professional support is provided to support midwives to practice to their full potential. The International Confederation of Midwives recognise that new graduate midwives should enter the profession with a defined set of basic or core competencies for practice and then, depending on the context they work in, midwives will in time develop or be supported to develop additional more complex skills. ${ }^{23}$

Ongoing supervision, support and professional development of midwives needs to be carefully considered. Accessing formal continuing professional development opportunities, which are often only available in urban centres is challenging in a low resource environment. ${ }^{24}$ Arranging for midwives to attend a course in person is expensive, with long distances to be travelled in order to attend. ${ }^{25}$ Creative ways of receiving continuing professional development, such as distance and online learning needs to be explored to cater to the needs of isolated 
midwifery graduates who work in rural and remote areas. An online system of professional development opportunities has been instigated successfully in several African nations. ${ }^{25}$ It is interesting to note the different messages that were obtained about the optimum method of learning. Nurses and midwives seem to prefer reading matter in PDF format rather than at faceto-face courses. ${ }^{25}$ As local contexts of practice and infrastructure requirements differ from country to country it would be necessary to examine the most appropriate and manageable mode for provision of continuing professional development in Papua New Guinea. Regulatory and professional bodies would be well positioned to coordinate and monitor opportunities for professional development. ${ }^{12}$

Providing continuing professional development that relies solely on the provision of self-directed reading materials is not recognised as bestpractice in terms of educational techniques. Interactive learning that includes reflection on practice has been recognised as effective in supporting moderate changes in practice, whereas didactic teaching is unlikely to influence professional practice. ${ }^{26}$ Interactive web based learning material may assist practice-based training, but is more difficult to support technically in LMIC due to lack of infrastructure and funding. A case study from South Africa explored the use of mobile phones in informal learning and concluded that delivery of learning through mobile phone platform can assist with developing problem solving skills; reflective practice activities; provide emotional support and promote belongingness; and, life-long learning. ${ }^{27}$ There is potential to utilise mobile phone technology for both graduate support programs and ongoing professional development in Papua New Guinea.

In addition to the provision of continuing professional development, graduates identified professional support as important in the development of confidence and competence especially in these early years after graduation. Graduates would have appreciated both face-toface supervision and telephone contact with senior colleagues. The need for support for new graduates is important as is the need for deployment soon after graduation. The State of the World's Midwifery (SoWMy2014) Report highlighted the need to improve deployment processes to enable the early building of confidence and competence. More than half of the countries examined in SoWMy2014 reported issues with delayed commencement into the workforce and it is likely that during this delay, skills, knowledge and confidence are lost. 28

Much work has already occurred in relation to strengthening the PNG Nursing Council as is evident in the $100 \%$ registration rates of the graduates in this study. Many organisations and reports support the improvements in regulation and the positive impact a strong regulatory system has on health care outcomes.12,14,28 A poorly functioning regulatory system is recognised as a barrier to the provision of quality midwifery care.12 Strengthening these important tenants of the midwifery profession will protect both the midwives working in the system and the women and families who access maternity care.

\section{CONCLUSION}

Nearly all of the midwifery graduates from the 2012 and 2013 cohort were working as midwives with $39 \%$ of them based in rural areas. Rural graduates generally worked as the only midwife. The midwives provided complex care with little support in their first year following midwifery registration and some were not able to practice all they had learned. There needs to be clarity concerning the scope of practice of midwives in all locations. The majority of graduates had no opportunity to participate in professional development related to midwifery since graduating.

Many graduates showed an in-depth understanding of the dire need of women in Papua New Guinea to have skilled midwives at birth and had made significant personal sacrifices in order to help women. Practical support in terms of suitable housing in both rural and urban areas and incentives to work in remote locations needs to be provided to improve the geographical spread of midwives across PNG. Supervision and mentoring from senior clinicians was highly valued and is commended. Graduates expressed the desire to work with senior clinicians in urban areas to gain confidence prior to providing midwifery care in remote areas. A formal graduate support program should be considered to further enhance quality midwifery care in Papua New Guinea.

\section{FUNDING}

This study was funded by Australian Aid. They provided funds for collection and interpretation of data. They had no role in the interpretation of 
data or in the writing and editing of this article. The authors indicate no competing interests.

\section{ACKNOWLEDGEMENTS}

Thank you to all the graduates who agreed to be part of this study and who shared their stories and experiences. We thank Rachel Smith who assisted with the final editing of the manuscript prior to submission.

\section{REFERENCES}

1. World Bank. PNG Health Workforce Crisis: A Call to Action. World Bank; 2013 Apr 26. Available from: http://www.worldbank.org/en/news/featu re/2013/04/26/papua-new-guinea-healthworkforce-crisis-a-call-to-action.

2. Dawson A, Howes, T., Gray, N. and Kennedy, E. Human resources for health in maternal, neonatal and reproductive health at community level: A profile of Papua New Guinea. Sydney: Human Resources for Health Knowledge Hub, University of New South Wales and Burnet Institute; 2011. Available from: https://sphcm.med.unsw.edu.au/sites/defa ult/files/sphcm/Centres_and_Units/MNRH_ PNG_Summary.pdf.

3. Homer C, Neill A. Midwifery Education in PNG: A discussion paper, 2015. Brief No 5. University of Technology Sydney World Health Organization's Collaborating Centre for Nursing, Midwifery and Health Development. Available from: https://www.uts.edu.au/sites/default/files/ Brief\%205\%20-

\%20Midwifery\%20education\%20discussio n\%20paper.pdf.

4. National Department of Health. Demographic Health Survey. Port Moresby, Papua New Guinea: National Department of Health; 2006.

5. National Department of Health. Ministerial Taskforce on Maternal Health in Papua New Guinea. Port Moresby; 2009.

6. Kruske S. A review of midwifery education standards and curriculum framework. Port Moresby: World Health Organization; 2006.

7. Dawson A, Kililo M, Geita L, Mola G, Brodie P, Rumsey M, Copeland F, Neill A, Homer CSE. Midwifery capacity building in Papua New Guinea: Key achievements and ways forward. Women and Birth. 2016;29(2):180 8. DOI: 10.1016/j.wombi.2015.10.007.

8. Papua New Guinea Nursing Council. PNG Nursing Council Report 2014. Port Moresby: PNG Nursing Council; 2015.

9. Moores A, Puawe P, Buasi N, West F, Samor M, Joseph N, Rumsey M, Dawson A, Homer CSE. Education, employment and practice: Midwifery graduates in Papua New Guinea. Midwifery. 2016; 41: 22-9. DOI: 10.1016/j.midw.2016.07.006.

10. Moores A, Catling C, West F, Neill A, Rumsey M, Samor M, Homer CSE. What motivates midwifery students to study midwifery in Papua New Guinea? Pacific Journal of Reproductive Health. 2015; 1(2). DOI: 10.18313/pjrh.2015.911.

11. Sandelowski M. Whatever happened to qualitative description? Research in Nursing and Health. 2000; 23: 334-40. DOI: 10.1002/1098240X(200008)23:4<334::AID -NUR9>3.0.CO;2-G.

12. Filby A, McConville F, Portela A. What prevents quality midwifery care? A systematic mapping of barriers in low and middle income countries from the provider perspective. PLoS ONE. 2016; 11(5): e0153391. DOI: 10.1371/journal.pone.0153391.

13. Australian Health Practitioners Regulatory Authority. Registration Standards. AHPRA; c2016. Available from: http://www.ahpra.gov.au/Registration/Reg istration-Standards.aspx.

14. International Confederation of Midwives. Global Standards for Midwifery Regulation 2011. ICM; c2017. Available from: http://internationalmidwives.org/what-wedo/regulation-core-documents/.

15. International Confederation of Midwives. Midwifery Regulation Toolkit. The Hague: ICM; 2016. Available from: http://internationalmidwives.org/what-wedo/regulation-core-documents/.

16. Monaghan J, Shorten A. The birth of 'MidPLUS': Australia's new national continuing professional development program for midwives. Women and Birth. 2008; 21(2): 55-64. DOI: 10.1016/j.wombi.2008.03.005.

17. Phillips C, Kenny, A., Esterman,A., Smith, C. A secondary data analysis examining the needs of graduate nurses in their transition 
to a new role. Nurse Education in Practice. 2014; 14. DOI: 10.1016/j.nepr.2013.07.007.

18. Lennox S, Jutel, Foureur M. The concerns of competent novices during a mentoring year. Nursing Research and Practice. 2012. Article ID 812542. DOI: $10.1155 / 2012 / 812542$.

19. Davis D, Foureur M, Clements V, Brodie P, Herbison, P. The self-reported confidence of newly graduated midwives before and after their first year of practice in Sydney, Australia. Women and Birth. 2012; 25. DOI: 10.1016/j.wombi.2011.03.005.

20. Skirton H, Stephen, N., Doris, F., Cooper, M., Avis, M. and Fraser, DM. Preparedness of newly qualified midwives to deliver clinical care: An evaluation of pre-registration midwifery education through an analysis of key events. Midwifery 2012; 28: e660-e6. DOI: 10.1016/j.midw.2011.08.007.

21. Clements V, Fenwick, J. and Davis, D. Core elements of transition support programs: The experiences of newly qualified Australian midwives. Sexual and Reproductive Healthcare. 2012; 3(4): 15562. DOI: $10.1016 /$ j.srhc.2012.08.001.

22. Ngongo C, Christie, K., Holden, J., Ford, C. and Pett, C. Striving for excellence: Nurturing midwives' skills in Freetown, Sierra Leone. Midwifery 2013; 29: 1230-4. DOI: 10.1016/j.midw.2013.01.013.

23. International Confederation of Midwives. Essential Competencies for Basic Midwifery Practice. The Hague: International Confederation of Midwives; 2010. Available from:

http://www.internationalmidwives.org/wh at-we-do/education-

coredocuments/essential-competenciesbasic-midwifery-practice/.

24. Hudspeth J, Curry C, Sacks Z, Surena C. Continuing Professional Development in Low-Resource Settings: Haiti as Example. Annals of Global Health. 2015; 81(2): 255-9. DOI: $10.1016 /$ j.aogh.2015.03.004.

25. Hosey KN, Kalula, A., Voss,J. Establishing an Online Continuing and Professional Development Library for Nurses and Midwives in East, Central, and Southern Africa. Journal of the Association of Nurses in AIDS Care. 2016; 27(3): 297-311. DOI: 10.1016/j.jana.2016.01.007.

26. Forsetlund L, Bjørndal A, Rashidian A, Jamtvedt G, O'Brien MA, Wolf FM, Davis D, Odgaard-Jensen J, Oxman AD. Continuing education meetings and workshops: effects on professional practice and health care outcomes. Cochrane Database of Systematic Reviews. 2009;2. Art. No.: CD003030. DOI: 10.1002/14651858.CD003030.pub2.

27. Pimmer C, Brysiewicz, $P$, Linxen, S, Walters, F, Chipps, J, Gröhbiel, U. Informal mobile learning in nurse education and practice in remote areas - A case study from rural South Africa Nurse Education Today. 2014; 34(11): 1398-404. DOI: 10.1016/j.nedt.2014.03.013.

28. United Nations Population Fund, International Confederation of Midwives and World Health Organisation. State of the World's Midwifery Report. Barcelona: UNFPA, ICM and WHO; 2014. Available from: http://www.unfpa.org/sowmy. 